\title{
Does Vaginal Anti-Incontinence Surgery Affect Sexual Satisfaction? A Comparison of TVT and Burch-Colposuspension
}

\author{
Oktay Demirkesen, Bulent Onal, Burcin Tunc, Bulent Alici, Bulent Cetinele \\ Department of Urology, University of Istanbul, Cerrahpasa School of Medicine, Istanbul, Turkey
}

\begin{abstract}
Objective: To evaluate the sexual satisfaction rates of women who underwent tension-free vaginal tape (TVT) procedure for stress urinary incontinence and compare it with the results of Burch-colposuspension.

Materials and Methods: A self-administered questionnaire was given to 81 patients who had undergone TVT or Burchcolposuspension at our institution to determine sexual satisfaction rates and reasons for dissatisfaction. Forty-seven patients in TVT group and 22 patients in Burch-colposuspension group were considered eligible for the study. The mean follow-up period and age of patients in TVT and Burch-colposuspension groups were 34 months, 51.5 years and 89 months, 52.9 years, respectively. The difference between the ages in the two groups was not statistically significant, while the difference between mean follow-up periods was significant $(\mathrm{p}=0.000)$.

Results: When evaluating sexual satisfaction, $73 \%$ in the TVT group and $86 \%$ in the Burch-colposuspension group did not report any difference in sexual satisfaction following surgery, while in the TVT group, $23 \%$ expressed negative and $4 \%$ positive changes, and in the Burch-colposuspension group 9\% expressed negative and 5\% positive post surgical changes. The differences in sexual satisfaction rates between the two groups were not considered significant. The majority (54\%) of those who expressed a negative change suffered from dyspareunia.

Conclusions: Although sexual satisfaction seems to be more adversely affected by TVT compared to Burch-colposuspension, the difference was not statistically significant. Further studies are required concerning different anti-incontinence techniques in order to arrive at more precise conclusions.
\end{abstract}

Key words: urinary incontinence, stress; surgical procedures, operative; sexual dysfunction, physiological

Int Braz J Urol. 2008; 34: 214-9

\section{INTRODUCTION}

Sexual dysfunction in women is a fairly common problem and one that occurs in as many women as in men. It is an important health problem that affects the quality of both women and their partners' lives $(1,2)$. Although the available literature on this subject has been increasing, less is known about female sexual dysfunction than male sexual dysfunc- tion (3). It has been observed in various studies that the anterior and distal parts of the vagina, which is the most innervated, play an important role in sexual function $(4,5)$.

Many surgeons currently prefer to use tension-free vaginal tape (TVT) procedure to treat stress urinary incontinence (SUI). However, the effect on sexual function of vaginal surgery for incontinence has not yet been clearly established and only limited 
data on this subject are reported in the literature (6-9). Altered sexual function might be attributed to vaginal surgery, which may cause vaginal narrowing or can damage the highly innervated anterior vagina (5).

The aim of this study was to use a questionnaire to evaluate any changes in sexual satisfaction of women who underwent a TVT procedure for SUI. The results of this evaluation were compared with the results from those women who had undergone surgery using a suprapubic anti-incontinence technique (Burch-colposuspension).

\section{MATERIALS AND METHODS}

Eighty-one patients who had undergone TVT procedure (between 1999 and August 2000) or Burch-colposuspension (between July 1994 and June 1998) at our institution were contacted by phone. Sixty-nine patients $(85 \%)$ who were sexually active pre-and postoperatively, had a partner, and a successful surgical outcome were invited for a hospital consultation. Forty-seven patients in the TVT group and 22 patients in the Burch-colposuspension group were considered eligible for the study. The mean age of the patients who underwent TVT was 51.5 years (median 51, range 38-68) whereas the mean age of the patients who underwent Burch-colposuspension was 52.6 years (median 52, range 36-67). Concomitant rectocele or cystocele repair was performed in 3 patients. All Burch-colposuspension surgery was performed under general anesthesia, whereas TVT was performed with either local or general anesthesia. The mean follow-up period of patients in TVT and Burch groups were 34 months (range 20-45) and 89 months (range 55-111), respectively (Mann Whitney$\mathrm{U}, \mathrm{p}=0.000)$.

Since no validated questionnaire in our language was available at that time, a questionnaire containing 8 questions was developed in our department to evaluate sexual satisfaction of the patients and their partners after the operation (Figure-1).

Chi-square, Fisher's exact, and Mann-Whitney $U$ tests were performed for statistical analysis. The Fisher's exact test was only used, instead of Chisquare test, when the expected number of patients in either category was less than five.

\section{RESULTS}

When evaluating sexual satisfaction, 34 of 47 patients (73\%) in TVT group and 19 of 22 patients $(86 \%)$ in Burch-colposuspension group did not report any difference after the operation. It was affected negatively or positively in $11(23 \%)$ and 2 (4\%) patients in the TVT group, and in $2(9 \%)$ and $1(5 \%)$ patients in the Burch-colposuspension group, respectively. The differences of sexual satisfaction rates between the two groups were not significant (Fisher's exact test; $p=0.137$ ) (Table-1). In the TVT group, of the 11 patients expressing negative effect, 5 were suffering from dyspareunia, 2 from sexual desire disorders, while 2 had vaginal dryness and 2 had orgasmic disorders. Both of the negatively effected patients in the Burch group also had dyspareunia (Table-2). None of the patients had declared any of these problems prior to the surgery.

When evaluating the sexual satisfaction of the partners, 45 of 47 patients' partners $(95.7 \%)$ in the TVT group and 22 of 22 patients (100\%) in the Burch-colposuspension group did not report any difference. Only one partner (2\%) in the TVT group mentioned that his sexual life deteriorated after the operation.

Thirty-six of 47 patients $(76.5 \%)$ in the TVT group and 19 of $22(86.3 \%)$ in the Burch-colposuspension group were satisfied with the operation, and 37 patients $(76.5 \%)$ in TVT group and $19(86.3 \%)$ in Burch-colposuspension group declared that, in the same circumstances, they would have undergone the surgery again and could recommend it to their relatives or friends.

\section{COMMENTS}

Sexual dysfunction in women is a fairly common problem and age, level of education, physical and mental health status seem to affect this situation. It is a health problem that affects both women's as well as their partners' quality of life (1). Urinary incontinence itself is also an important parameter that negatively affects all of the sexual functional parameters (10). Women who experience leakage during intercourse hope that their sexual function will improve follow- 
1) Are you sexually active or not?
a. Yes
b. No

2) Do you have a sexual partner?
a. Yes
b. No

3) Compare your present sexual satisfaction during intercourse with that before the operation.
a. Better
b. Same
c. Worse

4) If it is worse, what problems are you experiencing with your sexual life?

A. How is your sexual desire?
a. Better
b. Same
c. Worse

B. Do you feel any dryness during the intercourse?
a. Yes
b. No

C. Do you feel any pain during the intercourse?
a. Yes
b. No

D. Do you have orgasm during the intercourse?
a. Yes
b. No

5) For partner,

Compare the present sexual satisfaction during intercourse with that before the operation.
a. Better
b. Same
c. Worse

6) Are you satisfied with the outcome of the operation?
a. Yes
b. No

7) Would you want your partner to undergo this operation again if it were indicated?
a. Yes
b. No

8) Would you recommend this operation to your relatives or friends?
a. Yes
b. No

Figure 1-Questionnaire that was designed for the evaluation of the sexual function after anti-incontinence surgery.

ing surgery for SUI, and this affects their decision to undergo surgery (2).

However, surgery for pelvic prolapsus and SUI may cause sexual dysfunction due to vaginal narrowing and/or may alter vaginal innervation and cause sexual dysfunction (11). On the other hand, it is reported that abdominal surgery performed for urinary incontinence does not affect sexual function. However, by elevating the anterior vaginal wall and tilting the axis of vagina, sexual function may improve (12). For this reason, we compared the results of those patients who had undergone Burch- colposuspension while evaluating sexual function of the patients who had undergone TVT operation at our department. Patients who still had leakage were excluded from the study, because leakage during intercourse, itself is a factor that causes sexual dysfunction. One of the limitations of our study is the significant difference in follow-up period of the TVT and Burch-colposuspension groups. Therefore, further prospective randomized studies evaluating the sexual satisfaction rates are needed to compare different surgical techniques for the treatment of SUI. 
Table 1 - Satisfaction rates of the continent and sexually active women in TVT and Burch-colposuspension groups.

\begin{tabular}{|c|c|c|c|}
\hline & TVT (47) & Burch (22) & p Value* \\
\hline \multicolumn{4}{|c|}{ Sexual satisfaction during intercourse after surgery } \\
\hline Worse & $11(23 \%)$ & $2(9 \%)$ & \\
\hline Better & $2(4 \%)$ & $1(5 \%)$ & \\
\hline Same & $34(73 \%)$ & $19(86 \%)$ & $0.1374 *$ \\
\hline \multicolumn{4}{|l|}{ Sexual satisfaction of the partner after surgery } \\
\hline Worse & $1(2 \%)$ & - & \\
\hline Better & $2(4 \%)$ & - & \\
\hline Same & $44(94 \%)$ & $22(100 \%)$ & $0.6811 *$ \\
\hline Satisfied with the outcome of the operation & $35(74.5 \%)$ & $19(86.6 \%)$ & $0.355^{* *}$ \\
\hline Accept to undergo operation again & $36(76.5 \%)$ & $19(86.6 \%)$ & $0.523 * *$ \\
\hline Recommend it to their relatives or friends & $36(76.5 \%)$ & $19(86.6 \%)$ & $0.523 * *$ \\
\hline
\end{tabular}

$*$ = chi square $; *=$ Fisher exact test.

Table 2 - The reasons for dissatisfaction after TVT and Burch-colposuspension.

TVT Burch

\begin{tabular}{|c|c|c|}
\hline Sexual desire disorders & & \\
\hline Hypoactive sexual desire disorder & 2 & - \\
\hline Sexual aversion disorder & - & - \\
\hline Sexual arousal disorder & - & - \\
\hline Lubrication or vaginal dryness & 2 & - \\
\hline Orgasmic disorder & 2 & - \\
\hline Sexual pain disorder & & \\
\hline Dyspareunia & 5 & 2 \\
\hline Vaginismus & - & - \\
\hline Other sexual pain disorder & - & - \\
\hline Total & 11 & 2 \\
\hline
\end{tabular}

Lemack et al. evaluated the sexual function of 56 women after anterior vaginal wall surgery for SUI and found that the sexual lives of $18 \%$ of the women worsened following surgery (7). They also observed that postmenopausal women on hormone replacement therapy were more likely to be sexually active following surgery ( $46 \%)$ than those who were not on hormone replacement therapy (17\%) (7). In one of the prospective studies, Rogers et al. reported that sexual function did not improve after anti-incontinence surgery despite improvement of incontinence (13).

Many studies evaluating the sexual function after TVT showed conflicting results, with a reported sexual dysfunction after surgery ranging from 3 to $20 \%$ of cases $(8,14-19)$. We believe that the limitations of current methods of sexual function evaluation and different study design and patient selection criteria prevent a reliable comparison of results. Maatia et al. evaluated the sexual function of 43 sexually active women who underwent TVT and noted that $72 \%$ 
of women did not experience any difference, while sexual function in $5 \%$ of the patients had improved and $14 \%$ worsened(8). In this study, worsening of sexual satisfaction following surgery was not found to be due to surgical procedures but decreased libido and vaginal atrophy was due to decreased postmenopausal estrogen levels (8). Berglund et al. reported that there was no significant difference in sexual activity before and after surgery in women who had undergone surgery for SUI (20). Recently Shah et al. showed that overall sexual function did not change in women undergoing placement of a mid to distal polypropylene urethral sling (19). Wang et al. investigated the change of the patients' sexual function after the surgery for SUI, and compared the laparoscopic Burch-colposuspension with TVT (21). In this study they found that surgery adversely affected the patients' sexual life, with TVT having a lesser negative affect than Burch-colposuspension. In our study, when evaluating sexual satisfaction, $73 \%$ of women who underwent TVT operation did not experienced any difference. In $4 \%$ of patients, sexual satisfaction was improved, while in $23 \%$ of patients, it had worsened. In the Burch-colposuspension group the number of the patients who were adversely affected and reported a worsening of sexual satisfaction after the operation was lower (9\%) and not considered statistically significant. A total of 11 patients reported sexual dysfunction after vaginal-incontinence surgery (TVT) and, of these patients $45 \%$ described dyspareunia post-operatively while $18 \%$ had orgasmic disorder, $18 \%$ suffered from lubrication or vaginal dryness and $18 \%$ had decreased sexual desire. In the Burch-colposuspension group, 2 patients whose sexual lives had deteriorated after the operation reported dyspareunia. Recently, the study reported by Ghezzi et al. showed no significant difference in the incidence of dyspareunia (18). The relationship between dyspareunia and vaginal surgery is still unclear. Some authors have indicated that symptomatic vaginal narrowing is rare even in those patients undergoing simultaneous posterior repair $(7,12,22,23)$, while others have stated that the vaginal narrowing is primarily experienced when the posterior wall defect has been corrected with anti-incontinence surgery $(6,24)$. Haase et al. evaluated the influence of the operations for stress incontinence on sexual life and found that dyspareunia was observed in all of the patients in which posterior wall repair was performed during the operation (6). We also performed rectocele repair in 2 patients and cystocele repair in a patient concomitantly while performing TVT operation. None of these patients reported dyspareunia. Lemack et al. noted that the number of patients who suffered from dyspareunia preoperatively (29\%) decreased postoperatively $(20 \%)(7)$.

Another limitation of our study was that we were not able to use a validated questionnaire. Since there was not a validated Turkish version of one of the sexual function questionnaires, we created a questionnaire, which contained 8 questions in this study. To compare the success of anti-incontinence surgery and to evaluate the sexual function of women after these operations, validated questionnaires are important to standardize the studies. The Turkish version of the Female Sexual Function Index (FSFI) has recently been validated by the Turkish Andrological Society. Despite this limitation, we believe that our results provide a useful insight for clinicians when managing and counseling the patients who have undergone vaginal surgery for SUI.

\section{CONCLUSIONS}

Although sexual satisfaction seems to be more adversely affected by TVT compared to Burchcolposuspension, the difference was not statistically significant. Further studies are warranted concerning the different incontinence techniques in order to provide more precise conclusions.

\section{CONFLICT OF INTEREST}

None declared.

\section{REFERENCES}

1. Rosen RC, Taylor JF, Leiblum SR, Bachmann GA: Prevalence of sexual dysfunction in women: results of a survey study of 329 women in an outpatient gynecological clinic. J Sex Marital Ther. 1993; 19: $171-88$. 
2. Read S, King M, Watson J: Sexual dysfunction in primary medical care: prevalence, characteristics and detection by the general practitioner. J Public Health Med. 1997; 19: 387-91.

3. Basson R, Berman J, Burnett A, Derogatis L, Ferguson D, Fourcroy J, et al.: Report of the international consensus development conference on female sexual dysfunction: definitions and classifications. J Urol. 2000; 163: 888-93.

4. Hilliges M, Falconer C, Ekman-Ordeberg G, Johansson $\mathrm{O}$ : Innervation of the human vaginal mucosa as revealed by PGP 9.5 immunohistochemistry. Acta Anat (Basel). 1995; 153: 119-26.

5. O'Connell HE, Hutson JM, Anderson CR, Plenter RJ: Anatomical relationship between urethra and clitoris. J Urol. 1998; 159: 1892-7.

6. Haase P, Skibsted L: Influence of operations for stress incontinence and/or genital descensus on sexual life. Acta Obstet Gynecol Scand. 1988; 67: 659-61.

7. Lemack GE, Zimmern PE: Sexual function after vaginal surgery for stress incontinence: results of a mailed questionnaire. Urology. 2000; 56: 223-7.

8. Maaita M, Bhaumik J, Davies AE: Sexual function after using tension-free vaginal tape for the surgical treatment of genuine stress incontinence. BJU Int. 2002; 90: 540-3.

9. Weber AM, Walters MD, Piedmonte MR: Sexual function and vaginal anatomy in women before and after surgery for pelvic organ prolapse and urinary incontinence. Am J Obstet Gynecol. 2000; 182: 16105.

10. Aslan G, Köseoðlu H, Sadik O, Gimen S, Cihan A, Esen A: Sexual function in women with urinary incontinence. Int J Impot Res. 2005; 17: 248-51.

11. Paraiso MF, Ballard LA, Walters MD, Lee JC, Mitchinson AR: Pelvic support defects and visceral and sexual function in women treated with sacrospinous ligament suspension and pelvic reconstruction. Am J Obstet Gynecol. 1996; 175: 1423-30; discussion 1430-1.

12. Iosif CS: Sexual function after colpo-urethrocystopexy in middle-aged women. Urol Int. 1988; 43: 231-3.

13. Rogers RG, Kammerer-Doak D, Darrow A, Murray $\mathrm{K}$, Olsen A, Barber M, et al.: Sexual function after surgery for stress urinary incontinence and/or pelvic organ prolapse: a multicenter prospective study. Am J Obstet Gynecol. 2004; 191: 206-10. Retraction in: Am J Obstet Gynecol. 2006; 195: 1501.

14. Mazouni C, Karsenty G, Bretelle F, Bladou F, Gamerre M, Serment G: Urinary complications and sexual function after the tension-free vaginal tape procedure. Acta Obstet Gynecol Scand. 2004; 83: 955-61.
15. Yeni E, Unal D, Verit A, Kafali H, Ciftci H, Gulum M: The effect of tension-free vaginal tape (TVT) procedure on sexual function in women with stress urinary incontinence. Int Urogynecol J Pelvic Floor Dysfunct. 2003; 14: 390-4.

16. Elzevier HW, Venema PL, Lycklama á Nijeholt AA: Sexual function after tension-free vaginal tape (TVT) for stress incontinence: results of a mailed questionnaire. Int Urogynecol J Pelvic Floor Dysfunct. 2004; 15: 313-8.

17. Glavind K, Tetsche MS: Sexual function in women before and after suburethral sling operation for stress urinary incontinence: a retrospective questionnaire study. Acta Obstet Gynecol Scand. 2004; 83: 965-8.

18. Ghezzi F, Serati M, Cromi A, Uccella S, Triacca P, Bolis P: Impact of tension-free vaginal tape on sexual function: results of a prospective study. Int Urogynecol J Pelvic Floor Dysfunct. 2006; 17: 54-9.

19. Shah SM, Bukkapatnam R, Rodríguez LV: Impact of vaginal surgery for stress urinary incontinence on female sexual function: is the use of polypropylene mesh detrimental? Urology. 2005; 65: 270-4.

20. Berglund AL, Fugl-Meyer KS: Some sexological characteristics of stress incontinent women. Scand J Urol Nephrol. 1996; 30: 207-12.

21. Wang W, Zhu L, Lang JH: Study of sexual function in women after surgery for stress urinary incontinence. Zhonghua Fu Chan Ke Za Zhi. 2006; 41: 253-7.

22. Tunuguntla HS, Gousse AE: Female sexual dysfunction following vaginal surgery: myth or reality? Curr Urol Rep. 2004; 5: 403-11.

23. Porter WE, Steele A, Walsh P, Kohli N, Karram MM: The anatomic and functional outcomes of defect-specific rectocele repairs. Am J Obstet Gynecol. 1999; 181: 1353-8; discussion 1358-9.

24. Francis WJ, Jeffcoate TN: Dyspareunia following vaginal operations. J Obstet Gynaecol Br Commonw. 1961; 68: 1-10.

Accepted after revision:

December 17, 2007

\section{Correspondence address:}

Dr. Burcin Tunc

Merkez Mah, Huzur Sok No: 2/7

Sisli, Istanbul, Turkey

Fax: + 902125348689

E-mail: burcintunc@yahoo.com 